\title{
Application of in-house nested polymerase chain reaction for rapid diagnosis of tuberculous pleural effusion
}

\author{
Singh $A^{1}$, Kumar $A^{2}$, Chaturvedi $V^{3}$, Sharma $P^{4}$ \\ ${ }^{1}$ Dr Amit Singh*, Associate Professor, Department of Microbiology, ${ }^{2}$ Dr Adesh Kumar, Professor \& HOD, Department \\ of Pulmonary Medicine, ${ }^{3}$ Dr Vineet Chaturvedi, Associate Professor, Department of Pathology, ${ }^{4}$ Dr Pradeep Sharma, \\ Professor, Department of Biochemistry. All are affiliated with UPRIMS\&R, Saifai, Etawah, U.P.
}

Address for Correspondence: Dr Amit Singh, E-mail: dramitsingh.uprims@ gmail.com

\begin{abstract}
Tuberculous pleural effusion (TPE) is a common manifestation of extrapulmonary tuberculosis and is the most common cause of pleural effusion in many countries. Conventional diagnostic tests for detection of Mycobacterium tuberculosis in pleural fluid or pleural tissue, have known limitations. Hence, there is need for a newer, rapid diagnostic tests. Molecular techniques, detecting DNA of M. tuberculosis in pleural fluid have better sensitivity and could be a potent tool for rapid diagnosis of tuberculous pleural effusion. Objective: To evaluate Nested PCR protocol targeting $38 \mathrm{kDa}$ gene for rapid detection of $M$. tuberculosis complex in clinically suspected cases of TPE. Material and methods: A cross-sectional, prospective study was carried out at the tertiary care institute in a rural setup at western U.P. A total of 155 subjects with clinical suspicion of TPE enrolled during February 2015 to January 2016. About 10-20 ml of pleural fluid was collected and analysed for presence of $M$.tuberculosis by Z.N staining, culture on Lowenstein Medium (LJ), BacT/Alert 3D culture bottle and by Nested PCR targeting 38kDa gene of $M$. tuberculosis. Result: Off the 155 patients enrolled, $M$. tuberculosis was detected by AFB staining, LJ culture and BacT/Alert 3D system staining in $13(8.4 \%), 45(29 \%)$ and 72 (46.5\%) respectively. Diagnostic sensitivity of nested PCR (nPCR) was $60.6 \%$ and among smear positive and culture negative samples, sensitivity was $100 \%$ while in smear negative, culture negative it was $29.2 \%$. Conclusion: $38 \mathrm{kDa}$ based nested PCR offers alternative robust approach for rapid and accurate detection of $M$.tuberculosis in paucibacillary tuberculous pleural effusion specimens.
\end{abstract}

Keywords: 38kDa, BacT/Alert 3D system, Mycobacterium tuberculosis, nested PCR, Tuberculous pleural effusion

\section{Introduction}

Tuberculosis (TB) continues to be a major health problem globally, currently ranking the second most common cause of death due to an infectious disease, after only HIV/AIDS. In 2014, there were an estimated 9.6 million incident cases of TB (range, 9.1 million10.0 million) and 1.5 million $\mathrm{TB}$ deaths. India is one of the 22 'High Burden Countries' and along with Indonesia and China, accounts for $43 \%$ of global cases [1]. Among extrapulmonary tuberculosis, pleural TB is one of the most frequent manifestation and tuberculous pleural effusion occurs in up to $30 \%$ of patients with tuberculosis [2]. Diagnosis in an early stage of the disease is of utmost importance for treatment initiation and proper management of the patient. Therefore, it is

Manuscript received $4^{\text {th }}$ April 2016

Reviewed: $16^{\text {th }}$ April 2016

Author Corrected: $25^{\text {th }}$ April 2016

Accepted for Publication $8^{\text {th }}$ May 2016 imperative for clinical microbiology laboratories be able to quickly identify mycobacteria. However, the number of organisms in pleural effusion specimens obtained from majority of patients with tuberculous pleuritis is fairly low, with culture positivity seen in $<40 \%$ of cases and smear invariably being negative [3]. Polymerase chain reaction (PCR) based techniques provide high sensitivity by amplification of small quantity of DNA, and have been extensively evaluated for the detection of $M$. tuberculosis from clinical samples [4]. Substantial number of the tests described in the literature are based on amplification ofIS6110, an insertion element that is present in members of the $M$. tuberculosis complex [5-7]. Insertion Sequence 6110 is usually found at multiple sites in majority of $M$. tuberculosis strains which enhances the sensitivity of PCR. However, strains lacking even single copy of 
IS6110 has been reported [8] and thus, relying only on IS6110-based PCR is not prudent. Moreover, nested Polymerase chain reaction (nPCR) protocols has been shown to have an enhanced sensitivity over 1000 fold for detection of $M$. tuberculosis, in comparison to single round conventional PCRs [9]. To overcome these problems, we evaluated the potential use of an in-house nPCR protocol based on amplification of $38 \mathrm{kDa}$ gene, a house keeping gene of Mycobacterium tuberculosis, involved in phosphate transport [10], in comparison with BacT/Alert 3D, for rapid detection of $\mathrm{M}$. tuberculosis in tuberculous pleural effusion.

\section{Materials and Methods}

A cross-sectional, prospective study was carried out at the Department of Microbiology and Department of Pulmonary Medicine, UPRIMS\& R, Saifai, a tertiary care and teaching institute in a rural setup in western Uttar Pradesh. It was approved by the institute ethical committee. All the patients who were clinically diagnosed as pleural effusion, between February, 2015 to January 2016,were considered for the study. The inclusion criteria adopted in selection of patient were (i) patients with cough, fever, pleuritic chest pain, malaise (ii)chest X-rays showing evidence of pleural effusion with or without pulmonary infiltrates (iii) Ultrasound and C.T scan (Thorax) evidence of pleural effusion (iv) analysis of pleural fluid demonstrating straw colored fluid, total count more than 500 cells $/ \mathrm{mm}$, lymphocytic predominance $(>80 \%$ ), total protein $>5 \mathrm{gm} / \mathrm{dl}$, glucose concentration $<40 \mathrm{mg} / \mathrm{dl}$. Exclusion criteria consisted of patients already on antitubercular therapy, having contraindication to thoracocentesis viz. mechanically ventilated patient, non-cooperative patients, bleeding diathesis.

One hundred and fifty-five, non-repeated clinical samples from patients fulfilling the above criteria were collected and an informed consent was obtained. A detailed clinical history, physical examination, baseline laboratory investigations, history regarding present and past history of anti tubercular treatment (ATT), family history of tuberculosis and any other associated disease were taken in prescribed proforma. Among the 155 cases, $125(80.6 \%)$ cases had unilateral and 30(19.4\%) cases had bilateral effusions respectively.

Sample collection and processing: Under strict aseptic precautions, about $10-20 \mathrm{ml}$ of pleural fluid was collected and distributed into four sterile screw capped containers. First sample was analysed for estimation of glucose and protein levels. Second sample was utilized for cytology and cell count including total count and differential count. Third sample was utilized for mycobacterial detection by $\mathrm{AFB}$ stain and culture. Fourth sample was stored at $-20^{\circ} \mathrm{C}$ for PCR.

Pleural fluid samples were centrifuged at 3,000 rpm for 15 minutes and the deposit was processed for ZiehlNeelsen staining for AFB, culture for M. tuberculosis as per the standard bacteriological procedure. Briefly, 10 $\mathrm{mL}$ of each pleural fluid specimen was decontaminated with an equal amount of $4 \% \mathrm{NaOH}$ solution and was centrifuged at $3000 \mathrm{~g}$ for $20 \mathrm{~min}$ to collect the sediment. A portion of the deposit was used for preparation of smear to be stained by Ziehl Neelsen method and from the other portion, two plain Lowenstein-Jensen (LJ) slopes and BacT/Alert MP bottle were inoculated. LJ slopes were incubated at $37^{\circ} \mathrm{C}$ for maximum of 8 weeks before declaring them negative for M. tuberculosis.

BacT/Alert bottles were loaded in BacT/Alert 3D system (bioMerieux, France). Instrument automatically monitors the bottle every 10 minutes and detects any change of color at the bottom of bottle and flags it as positive. All positive flagged bottles were unloaded, vortexed and $0.5 \mathrm{ml}$ of fluid, aspirated for confirmation of mycobacterial growth by Z.N staining. AFB grown on LJ\& BacT/Alert bottle were further identified as Mycobacterium tuberculosis, based on slow growth rate, absence of pigmentation, positive Niacin test and growth inhibition on LJ medium with p-nitrobenzoic acid. Standard strain M. tuberculosis complex, H37Rv ATCC TM No. 27294 was used as positive control.

DNA extraction: Extraction of DNA was done by the CTAB (cetyl-tri-methyl-ammonium bromide)-phenol chloroform extraction method [11]. First the pleural aspirate was centrifuged at 10,000 rpm for $10 \mathrm{~min}$. The supernatant was discarded and the pellet suspended in $567 \mu \mathrm{L}$ of TE (Tris EDTA, pH 7.4) buffer. Then $30 \mu \mathrm{L}$ of $10 \%$ SDS (sodium dodecyl sulfate) and $3 \mu \mathrm{L}$ proteinase $\mathrm{K}(20 \mathrm{mg} / \mathrm{mL})$ was added and vortexed, then incubated at $37^{\circ} \mathrm{C}$ for $1 \mathrm{~h}$. After incubation, $100 \mu \mathrm{L}$ of 5 $\mathrm{M} \mathrm{NaCl}$ and $80 \mu \mathrm{L}$ of high-salt CTAB buffer (containing $4 \mathrm{M} \mathrm{NaCl}$ ), $1.8 \% \mathrm{CTAB}$ was added and mixed followed by incubation at $65^{\circ} \mathrm{C}$ for $10 \mathrm{~min}$. An approximate equal volume $(700-800 \mu \mathrm{L})$ of chloroformisoamyl alcohol (24:1) was added, mixed thoroughly and centrifuged for 5 minutes in a microcentrifuge at $12,000 \mathrm{rpm}$. The aqueous viscous supernatant was carefully aspirated and transferred to a newmicrocentrifuge tube. An equal volume of phenol: 
chloroform-isoamyl alcohol $(1: 1)$ was added followed by a 5 minute spin at 12,000 rpm. The supernatant was separated and then mixed with 0.6 volume of isopropanol to get a precipitate. The precipitated nucleic acids were washed with $75 \%$ ethanol, dried and resuspended in $100 \mu \mathrm{L}$ of TE buffer.

PCR amplification protocol: $38 \mathrm{kDa}$ nested PCR was carried out as per method described by Miyazaki Y et al [9].Primers targeting the gene sequence that encoded the $38 \mathrm{kDa}$ protein of M.tuberculosis were used as described by Sjobring et al [12]. The sequence of TB PCR primer pairs for $1^{\text {st }}$ and $2^{\text {nd }}$ round of amplifications were: Forward Primer MTb1: 5' -ACCACCGAGC GGTTCGCCTGA-3'; Reverse Primer MTb2: 5' -GATC TGCGGGTCGTCCCAGGT-3'; Internal Forward Primer NF: 5'-TGACGTTGGCGGAGACCG-3'; Internal Reverse Primer NR: 5'-ATGGTG CCCT GGTACATG-3'. The first amplification reaction mixture consisted of $90 \mu \mathrm{l}$ of master mix $(50 \mathrm{mM}$ $\mathrm{KCl}, 10 \mathrm{mM}$ Tris- $\mathrm{HCl}, 1.5 \mathrm{mM} \mathrm{MgCl}_{2}, 0.3 \mathrm{mM}$ each of dNTP, 100 pmol each of primer MT1 \& MT2, $2.5 \mathrm{u}$ of Taq polymerase) and $10 \mu \mathrm{l}$ of target DNA.

The PCR amplification was done in a thermal cycler (XP Cycler, Bioer Technology, China). For 38kDa gene amplification, nested PCR was performed. The cycling parameter were, denaturation at $94^{\circ} \mathrm{C}$ for $1 \mathrm{~min}$, annealing at $63^{\circ} \mathrm{C}$ for $90 \mathrm{sec}$ and extension at $72^{\circ} \mathrm{C}$ for
$1 \mathrm{~min}$. For the second PCR, $10 \mu \mathrm{l}$ from the first PCR was sampled and mixed with $90 \mu 1$ of freshly prepared reaction mixture (containing Primers NF \& NR). This was followed by same procedures used to obtain the first PCR product. Both cycles were run for 35 cycles.

PCR products were analysed by electrophoresis in $2 \%$ agarose gel, stained with ethidium bromide and documented by gel documentation system (Gel Doc $\mathrm{XR}+$ System ${ }^{\circledR}$, Bio-Rad, USA). For each amplification a positive control containing DNA extracted from reference strain M.tb $\mathrm{H}_{37 R_{\mathrm{v}}}$ and negative control containing molecular grade water (HiMedia, India) was run. The presence of $419 \mathrm{bp} \& 322 \mathrm{bp}$ fragments in first and second PCR indicated a positive test ( $M$. tuberculosis complex).

Statistical analysis: The data was entered in Microsoft excel computer program. The analysis was done by using IBM SPSS Statistics ver 21 program. The results

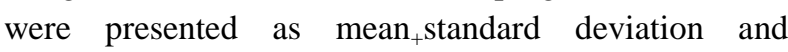
percentages. The sensitivity, specificity, positive predictive value and negative predictive values were calculated with a $95 \%$ confidence interval $(95 \% \mathrm{CI})$ using the standard formula, keeping combination of Solid and liquid culture as 'Gold Standard' [13]. Z score was calculated for comparison between two proportions. In our study, $\mathrm{p}$ value $<0.05$ was considered as significant.

\section{Results}

Out of 155 patients enrolled in the study, $112(72.25 \%)$ were males and $43(27.75 \%)$ were females. The mean age of presentation was $45 \pm 20.5$ years. Majority of the patients were in the age group $>50$ years $(42.6 \%)$, minimum age of 9 years and the maximum 90 years (Table 1). Fourteen patients (9\%) had past history of tuberculosis and 25 patients (16.1\%) had family history of being treated for tuberculosis. Most common symptom was cough (131/155;84.5\%), followed by fever $(125 / 155 ; 80.6 \%)$,chest pain $(112 / 155 ; 73.5 \%)$, dyspnea $(49 / 155 ; 31.6 \%)$, expectoration $(41 / 155$; $26.4 \%)$. Right side pleural effusion was seen among 75.6\% (93/125) cases. Mantoux test was positive in 105 (67.4\%) patients.

Table 1: Age and sex distribution of clinically diagnosed Tubercular Pleural effusion.

\begin{tabular}{|l|l|l|l|}
\hline Age Group & Male $(\mathbf{n}=\mathbf{1 1 2})$ & Female $(\mathbf{n}=\mathbf{4 3})$ & Total $(\mathbf{n}=\mathbf{1 5 5})$ \\
\hline$<25$ & 22 & 10 & 32 \\
\hline $25-50$ & 45 & 12 & 57 \\
\hline$>50$ & 45 & 21 & 66 \\
\hline
\end{tabular}

Acid fast bacilli were observed in only 13 pleural fluids. The detection rate of AFB smear was $8.4 \%$. Growth on LJ culture was obtained from 45 samples while BacT/Alert yielded additional 27 culture. Nested PCR detected M.tuberculosis in 94 samples (Figure 1). Overall detection rate for LJ culture, BacT/Alert 3D system and PCR was 29\%, $46.5 \%, 60.65 \%$ respectively. 
Figure 1: Amplification of 322bp product of M.tuberculosis by nested PCR targeting 38kDa region among samples of TPE on $2 \%$ gel electrophoresis.

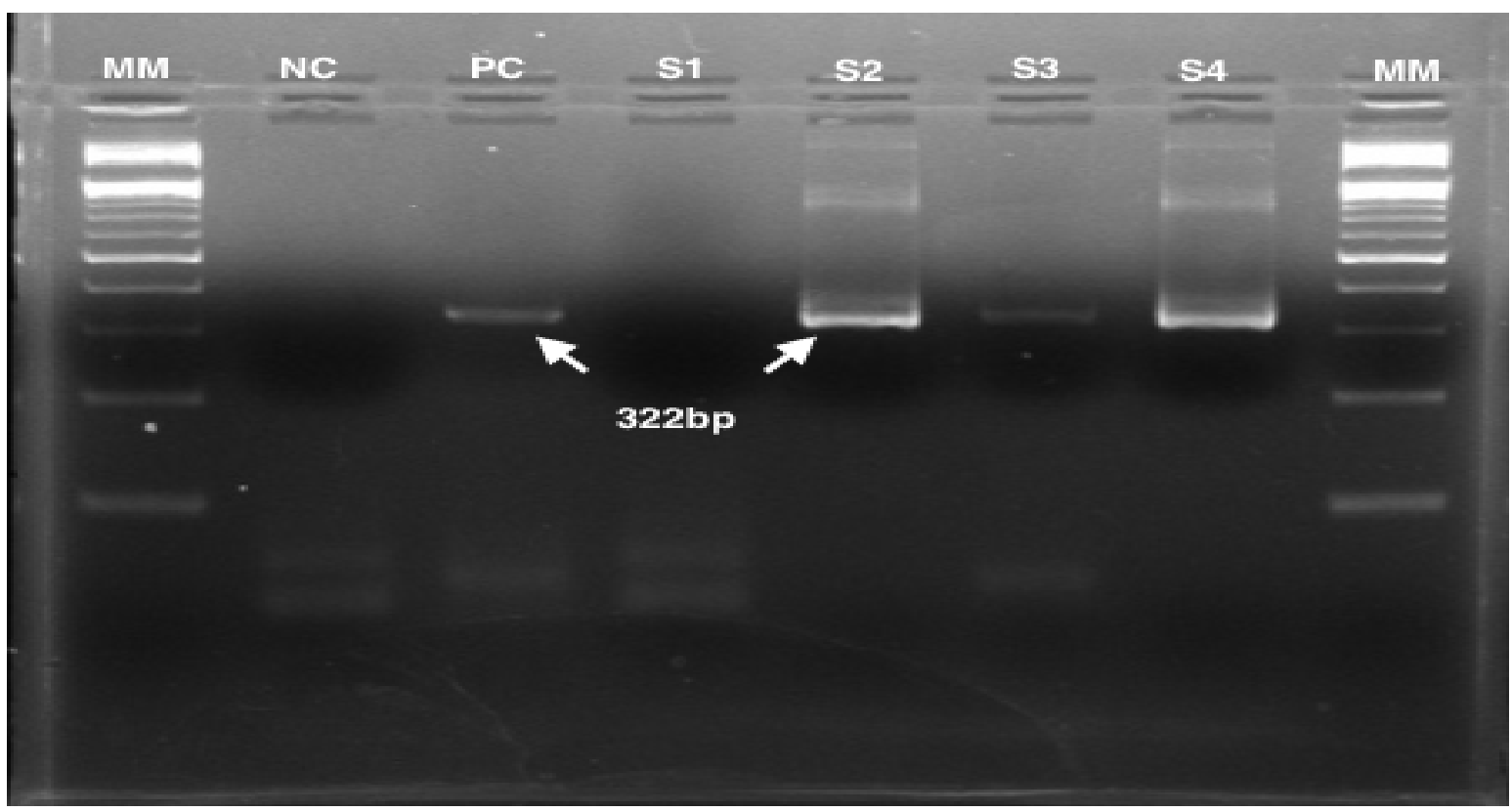

MM: Molecular marker 100bp, NC: Negative control, PC: Positive control (M.tb H37Rv strain), S1: Negative sample, S2,S,S4: Samples positive for 38kDa gene (M.tuberculosis).

Out of 155 samples, 13 were AFB smear positive and nPCR gave 100\% concordance (sensitivity of PCR 100\%) result and among 142 smear negative cases, PCR was positive in 81(57\%) cases. LJ culture and BacT/Alert system added another 33 positive cases and PCR sensitivity among these smear negative, LJ culture and BacT/Alert positive was 90.9\% (30/33). Among 13 AFB smear positive cases, one (7.7\%) was negative by both LJ and BacT/Alert system, however PCR was positive (100\% sensitivity) in this case. PCR was also $100 \%$ (27/27) sensitive in detecting those cases which were negative by culture but positive by BactT/Alert system. Overall, 72 cultures were positiveby either LJ or BacT/Alert 3D and PCR was positive in $95.84 \%$ (69/72) cases. In 82 smear negative \& culture negative cases, PCR detected 24 positive cases and had sensitivity of $29.26 \%$ (Table 2 ).

Table-2: Comparison of diagnostic sensitivity of nPCR with other tests.

\begin{tabular}{|l|l|l|l|l|}
\hline \multirow{2}{*}{ Test } & \multirow{2}{*}{ No. $(\boldsymbol{\%})$} & \multicolumn{2}{l|}{ N PCR result } & Sensitivity of \\
\cline { 3 - 5 } & & Positive & Negative & nPR $(\boldsymbol{\%})$ \\
\hline Smear +ve & $13(8.4)$ & 13 & 0 & 100 \\
\hline Smear -ve & $142(91.6)$ & 81 & 61 & 57.0 \\
\hline LJ culture+ve & $45(29)$ & 42 & 3 & 93.3 \\
\hline LJ culture -ve & $110(71)$ & 52 & 58 & 47.2 \\
\hline BacT/Alert +ve & $72(46.5)$ & 69 & 3 & 95.8 \\
\hline BacT/Alert -ve & $83(53.5)$ & 25 & 58 & 30.1 \\
\hline Smear+veLJ+ve BacT/Alert +ve & $12(7.8)$ & 12 & 0 & 100 \\
\hline Smear+ve LJ-ve BacT/Alert -ve & $1(0.6)$ & 1 & 0 & 100 \\
\hline Smear -ve LJ +ve BacT/Alert +ve & $33(22.5)$ & 30 & 3 & 90.9 \\
\hline Smear -ve LJ -veBactT/Alert +ve & $27(16.1)$ & 27 & 0 & 100 \\
\hline Smear -ve LJ-ve BacT/Alert -ve & $82(52.9)$ & 24 & 42 & 29.2 \\
\hline
\end{tabular}

Considering culture positivity (LJ \& BacT/Alert 3D system) as 'Gold standard', the sensitivity, specificity, positive predictive value (PPV) and negative predictive value (NPV) are shown in Table 3. AFB smear had overall sensitivity and specificity of $16.7 \%$ and $98.8 \%$ while sensitivity and specificity of nPCR was $95.83 \%$ and $69.88 \%$. 
Table 3: Comparison of sensitivity and specificity of nPCR, Smear microscopy and culture positivity.

\begin{tabular}{|c|c|c|c|c|c|c|c|}
\hline \multirow{2}{*}{\multicolumn{2}{|c|}{ Test }} & \multicolumn{2}{|c|}{$\begin{array}{l}\text { LJ \& BacT/Alert culture } \\
\text { for M.tuberculosis }(n=72)\end{array}$} & \multirow{2}{*}{$\begin{array}{l}\text { Sensitivity \% } \\
(95 \% \text { CI })\end{array}$} & \multirow{2}{*}{$\begin{array}{l}\text { Specificity \% } \\
(95 \% \text { CI })\end{array}$} & \multirow{2}{*}{$\begin{array}{l}\text { PPV\% } \\
(95 \% \text { CI })\end{array}$} & \multirow{2}{*}{$\begin{array}{l}\text { NPV\% } \\
(95 \% \text { CI })\end{array}$} \\
\hline & & Positive & Negative & & & & \\
\hline \multirow{2}{*}{ nPCR } & $+\mathrm{ve}$ & 69 & 25 & \multirow{2}{*}{$\begin{array}{l}95.83 \\
(88.3,99.1)\end{array}$} & \multirow{2}{*}{$\begin{array}{l}69.88 \\
(58.8,79.4)\end{array}$} & \multirow{2}{*}{$\begin{array}{l}73.4 \\
(63.3,82)\end{array}$} & \multirow{2}{*}{$\begin{array}{l}95.0 \\
(86.2,98.9)\end{array}$} \\
\hline & -ve & 3 & 58 & & & & \\
\hline \multirow{2}{*}{ Smear } & +ve & 12 & 1 & \multirow{2}{*}{$\begin{array}{l}16.7 \\
(8.9,27.3)\end{array}$} & \multirow{2}{*}{$\begin{array}{l}98.8 \\
(93.4,99.9)\end{array}$} & \multirow{2}{*}{$\begin{array}{l}92.31 \\
(63.9,99.8)\end{array}$} & \multirow{2}{*}{$\begin{array}{l}57.75 \\
(49.1,65.9)\end{array}$} \\
\hline & -ve & 60 & 82 & & & & \\
\hline
\end{tabular}

\section{Discussion}

Pleural TB accounts for $3-25 \%$ of patients with tuberculosis ${ }^{3}$, and tubercular pleurisy is the most common etiology of pleural effusion [14]. The pleural effusion is due to paucibacillary mycobacterial infection within the pleural space. The tubercular bacilli are acquired from initial parenchymal lesions and results in an immunological response that results in an increase pleural fluid formation and decrease pleural fluid removal [2]. If left untreated, TPE can develop into active tuberculosis [14] and hence, it is imperative to make rapid and accurate diagnosis for TPE and for initiation of treatment.

The conventional diagnosis of pleural TB by identifying tubercle bacilli in pleural fluid and pleural biopsy specimens or by demonstrating granulomas in pleural tissue lack sensitivity and are time-consuming [15]. In aspirates from TPE, organisms are rarely seen on $\mathrm{ZN}$ microscopy because of paucibacillary nature of the disease. In our study, AFB were seen in 13 (8.4\%) cases and among these cases, 12 were culture positive and one was culture negative by both LJ and BacT/Alert 3 $\mathrm{D}$ system. The culture negative case could be due to the presence of non-viable mycobacterium in partially treated patients or due to exposure to harsh chemicals during decontamination process [16]. All smear positive cases were also positive by PCR (100\% sensitivity).

In our study, mycobacterial culture positivity on LJ medium was positive in $29 \%$ and on BacT/Alert $3 \mathrm{D}$ automated system was $46.5 \%$. All positive LJ cultures were also positive by BacT/Alert 3D system. The diagnostic yield of pleural effusion cultures was slightly higher in our study than previously reported value 7$35 \%$ [17-20]. This discrepancy may be due to use of solid LJ cultures in most studies or differences in methods of decontamination during processing. Moreover, liquid cultures have been shown to have better isolation rates, faster results than solid cultures $[21,22]$ but higher contamination rates. In our study, contamination rate for liquid culture and $\mathrm{LJ}$ culture was $7 \%$ and $3.8 \%$ and mean time to detection was 3.2 weeks and 4.6 weeks respectively. Direct examination of pleural fluid by $\mathrm{ZN}$ staining requires bacillary load of more than $10,000 / \mathrm{ml}$ and thus has a low sensitivity. Although culture is more sensitive, it also requires minimum of 10 viable bacilli $/ \mathrm{ml}$. Studies done on pleural biopsy specimen have reported higher sensitivity $(70-85 \%)$, but the procedure may have complications and are not entirely risk free [14]. Currently, the most reliable method for diagnosis of TPE is detection of M. tuberculosis in pleural fluid or tissue.

Rapid diagnosis of TPE is of paramount importance for reduction of morbidity and mortality. Studies have documented PCR as a rapid and sensitive method for the detection of mycobacterial DNA in tubercular pleural effusions $[18,23,24]$. The utility of PCR for the diagnosis of TBE has been evaluated using gene targets such as IS6110, 16S rRNA, GCRS, $65 \mathrm{kDa}$ protein gene, MPB-64 protein gene, dnaJ and $\operatorname{dev} R$ with varying sensitivities $(17.1 \%-78 \%)$ and specificities (90\%-100\%) [4,25-28]. Most studies have evaluated the performance of PCR based on IS6110 insertion sequence, which are usually found in multiple copies in M. tubercuolosis genome.

However, mycobacterial strains from various geographical regions have shown complete absence or low copy number of these insertion sequence [8, 29,30]. In present study, we followed the technique of in-house nested PCR as described by Miyazaki Y et al [9] using primers targeting $38 \mathrm{kDa}$ 'protein antigen b' gene for amplification. It can detect small amount of DNA as $10 \mathrm{fg} \approx 2-3$ organisms and is highly specific [31]. Our nested PCR showed positivity of $60.6 \%$, which was significantly higher than that of LJ culture and BacT/Alert 3D $(\mathrm{z}=5.56 \mathrm{p}<0.05 \mathrm{nPCR}$ vs LJ and $\mathrm{z}$ score $=2.5, \mathrm{p}<0.05 \mathrm{nPCR}$ vs BacT/Alert 3D). Detection rate of our nested PCR were higher than Liu et 
al(43.3\%)[14], Kumar et al(51\%)[32] and similar to Villegas et al (60.7\%) [27]. Negiet al [33] reported a higher sensitivity of $71.3 \%$ using nPCR protocol targeting $38 \mathrm{kDa}$ gene among extrapulmonary specimen. Most studies have evaluated nPCR targeting IS6110 and thus depending upon presence or absence of IS6110, there is variability in detection rates. Our data suggests that $\mathrm{nPCR}$ is more sensitive than conventional methods but may not detect all cases.

All smear positive and culture positive samples were positive by PCR. Among $33 \mathrm{LJ}$ and BacT/Alert system culture positive samples, PCR was positive in $90.9 \%$ (30) cases. Three cultures positive samples were negative by PCR and this could be attributed to presence of PCR inhibitors, fragmentation of target sequences during DNA extraction. Among the 83 culture negative samples PCR was positive in 25 $(30.1 \%)$ samples. In comparison to the 'Gold standard' i.e. culture positivity in liquid as well as solid medium in our study, the sensitivity and specificity were $95.83 \%, 69.88 \%$, respectively. Studies conducted by ParandamanV et al [34], Jatana SK et al [35], Takagi N et al [36], have also shown similar results where sensitivity near $100 \%$ and specificity varied from 75 $90 \%$. Specificity of PCR in our study was lower, it could be due false positivity as PCR can detect DNA of dead bacilli in recently treated pulmonary/ pleural TB patient or could be due to cross contamination during initial processing or carry over contamination by amplicons. The assay specificity can be further improved by use of the dUTP-uracil glycosylase system and by conducting nPCR by single tube method.

Our study suggests that nested PCR based on detection of 38k Da gene of Mycobacterium tuberculosis can serve as a reliable and rapid tool for the diagnosis of TPE. Collaboration of clinical and laboratory findings in parallel with the nested PCR results aids to the presumptive diagnosis of TPE in cases where culture and AFB staining are negative and diagnosis is a big challenge.

\section{Conclusion}

Our study emphasizes thatnPCR based on $38 \mathrm{kDa}$ gene would definitely be useful for the diagnosis of tuberculous pleural effusion especially in patients where conventional diagnostic methods fails and where the provisional diagnosis of tuberculosis is made on account of clinical presentation and histology/cytology examination without evidence of AFB.
Funding: Nil, Conflict of interest: None initiated. Permission from IRB: Yes

\section{References}

1. Global TB report 2015 [Internet]. Washington: World Health Organisation. 2015. [cited 2016 March 5]. Available fromhttp://www.who.int/tb/publications/ global_report/en/.

2. Vorster MJ, Allwood BW, Diacon AH, Koegelenberg CF. Tuberculous pleural effusions: advances and controversies. J Thoracic Dis. 2015;7(6):981-91.

3. Light RW. Update on tuberculous pleural effusion. Respirology2010;15(3):451-8.

4. Chakravorty S, Dudeja M, Hanif M, Tyagi JS. Novel multipurpose methodology for detection of extrapulmonary specimens by smear microscopy, culture and PCR. J Clin Microbiol. 2005;43(6):2697702.

5. Makeshkumar V, Madhavan R, Narayan S. Polymerase chain reaction targeting insertion sequence for diagnosis of extrapulmonary tuberculosis. Indian $\mathbf{J}$ Med Res. 2014; 139(1):161-6.

6. Maurya AK, Kant S, Nag VL, Kushwaha R, Dhole TN. Detection of $123 \mathrm{bp}$ fragment of insertion element IS6110 Mycobacterium tuberculosis for diagnosis of extrapulmonary tuberculosis. Indian J Med Microbiol. 2012;30(2):182-6.

7. Sekar B, Selvaraj L, Alexis A, Ravi S, Arunagiri K, Rathinavel L. The utility of IS6110 sequence based polymerase chain reaction in comparison to conventional methods in the diagnosis of extrapulmonary tuberculosis. Indian J Med Microbiol. 2008;26(4):352-5.

8. Huyen MN, Tiemersma EW, Kremer K, de Haas P, Lan NT, Sola C, et al. Characterisation of Mycobacterium tuberculosis isolates lacking IS6110 in Viet Nam. Int J Tuberc Lung Dis. 2013; 17(11):147985 .

9. Miyazaki Y, Koga H, Kohno S, Kaku M. Nested polymerase chain reaction for detection of Mycobacterium tuberculosis in clinical samples. J Clin Microbiol.1993;31(8):2228-32. 
10. Kulkarni S, Singh P, Memon A, Natraj J, Kanade S, Kelkar R, et al. An in-house multiplex PCR test for the detection of Mycobacterium tuberculosis, its validation \& comparison with a single target TB-PCR kit. Indian J Med Res. 2012;135(5):788-94.

11. Somerville W, Thibert L, Schwartzman K, Behr MA. Extraction of Mycobacterium tuberculosis DNA: a question of containment. J Clin Microbiol. 2005;43(6): 2996-7

12. Sjobring $\mathrm{U}$, Mecklenburg $\mathrm{M}$, Andersen $\mathrm{AB}$, Miorner H. Polymerase chain reaction for detection of Mycobacterium tuberculosis.J Clin Microbiol. 1990;28(10):2200-04.

13. Piersimoni C, Scarparo C, Callegaro A, Passerine Tosi CP, Nista D, et al. Comparison of MB/BacT ALERT 3D system with radiometric BACTEC system and Lowenstein-Jensen medium for recovery and identification of mycobacteria from clinical specimens: a multicenter study. J Clin Microbiol.2001;39(2):651-7.

14. Liu KT, Su WJ, Preng RP. Clinical utility of polymerase chain reaction for diagnosis of smearnegative pleural tuberculosis. J Chin Med Assoc. 2007;70(4):148-51.

15. Light RW. Pleural diseases. Baltimore: Lippincott Williams and Wilkins; 2001. p. 182-95.

16. Nagesh BS, Sehgal S, Jindal SK, Arora SK. Evaluation of polymerase chain reaction for detection of Mycobacterium tuberculosis in pleural fluid. Chest. 2001; 119(6):1737-41.

17. Conde MB, Loivos AC, Rezende VM, Soares SL, Mello FC, Reingold AL. Yield of sputum induction in the diagnosis of pleural tuberculosis. Am J RespirCrit Care Med.2003;167(5):723-5.

18. Reechaipichitkul W, LulitanondV,Sungkeeree S, Patjanasoontorn B. Rapid diagnosis of tuberculous pleural effusion using polymerase chain reaction. Southeast Asian J Trop Med Public Health. 2000;31(3): 509-14.

19. Shital P, Gajanan H, Rujuta A. Role of nucleic acid amplification tests (NAATs) in tuberculous pleural effusion: where it fits in routine diagnostic workup? J Cell SciTher. 2014. 5: 169. doi:10.4172/21577013.1000169.
20. Diacon AH, Van de Wal BW, Wyser C, Smedema JP, Bezuldenhout J, Bollinger CT, et al. Diagnostic tools in tuberculous pleurisy: a direct comparative study. EurRespir J. 2003;22(4):589-91.

21. Hillemann D, Richter E, Rusch-Gerdes S. Use of the BACTEC Mycobacteria Growth Indicator Tube 960 automated system for recovery of mycobacteria from 9,558 extrapulmonary specimens, including urine samples. J Clin Microbiol. 2006; 44(11):4014-7.

22. Lu D, Heeren B, Dunne WM. Comparison of the automated Mycobacteria Growth Indicator Tube System (BACTEC 960 / MGIT) with Löwenstein-Jensen medium for recovery of mycobacteria from clinical specimens. Am J ClinPathol. 2002;118(4):542-5.

23. Kalaiselve G, Rajendran K. Rapid diagnosis of tuberculous pleural effusion by IS6110 sequence based PCR. IOSR Journal of Dental and Medical Science. 2013;12(6):50-4.

24. Cheng VC, Yam WC, Hung IF, Woo PC, Lau SK, Tang BS, et al. Clinical evaluation of polymerase chain reaction for the rapid diagnosis of tuberculosis. J Clin Path. 2004;57(3): 281-5.

25. Moon JW, Chang YS, Kim SK, Kim YS, Lee HM, Chang J. The clinical utility of polymerase chain reaction for diagnosis of pleural tuberculosis. Clin Infect Dis. 2005; 41(5):660-6.

26. Lima DM, Colares JK, da Fonseca BA. Combined use of the polymerase chain reaction and detection of adenosine deaminase activity on pleural fluid improves the rate of diagnosis of pleural tuberculosis. Chest. 2003;124(3): 909-14.

27. Villegas MV, Labrada LA, Saravia NG. Evaluation of polymerase chain reaction, adenosine deaminase, and interferon-gamma in pleural fluid for the differential diagnosis of pleural tuberculosis. Chest. 2000; 118(5):1355-64.

28. Srivastav R, Kumar D, Waskar MN, Sharma M, Katoch VM, Srivastav BS. Identification of a repetitive sequence belonging to a PPE gene of Mycobacterium tuberculosis and its use in diagnosis of tuberculosis. $\mathbf{J}$ Med Microbiol. 2006; 55(Pt 8):1071-7.

29. Dale JW, Al-Ghusein H, Al-Hashmi S, Butcher P, Dickens AL, Drobniewski F, et al. Evolutionary 
relationships among strains of Mycobacterium tuberculosiswith few copies of IS6110.J Bacteriol. 2003; 185(8):2555-62.

30. Thangappah RB, Paramasivan CN, Narayan S. Evaluating PCR, culture \& histopathology in the diagnosis of female genital tuberculosis. Indian J Med Res. 2011;134:40-6.

31. Kulkarni SP, Jaleel MA, Kadival GV. Evaluation of an in-house developed PCR for diagnosis of tubercular meningitis in Indian children. J Med Microbiol. 2005;54(pt4):369-73.

32. Kumar P, Sen MK, Chauhan DS, Katoch VM, Singh S, Prasad HK. Assessment of n-PCR assay in diagnosis of pleural tuberculosis: detection of $M$. tuberculosis in pleural fluid and sputum collected in tandem. PLoS ONE 5(4): e10220. doi:10.1371 /journal.pone.0010220
33. Negi SS, Anand R, Pasha ST, Gupta S, Blasir SF, Khare $S$, et al. Diagnostic potential of IS6110, $38 \mathrm{kda}$, $65 \mathrm{kda}$ and $85 \mathrm{~B}$ sequence based polymerase chain reaction in the diagnosis of Mycobacterium tuberculosis in clinical specimens. Indian J Med Microbiol. 2007; 25(1):43-9.

34. Parandaman V, Narayanan S, Narayanan PR. Utility of polymerase chain reaction using two probes for rapid diagnosis of tubercular pleuritis in comparison to conventional methods. Indian J Med Res. 2000; 112:4751.

35. Jatana SK, Nair MN, Lahiri KK, Sarin NP. Polymerase chain reaction in the diagnosis of tuberculosis. Ind. Pediatr. 2000;37(4):375-82.

36. Takagi N, Hasegawa Y, Ichiyama S, Shibagaki T, Shimokata K. Polymerase chain reaction of pleura biopsy specimens for rapid diagnosis of tuberculous pleurisy. Int J Tuberc Lung Dis.1998;2(4): 338-41.

\section{How to cite this article?}

Singh A, Kumar A, Chaturvedi V, Sharma P. Application of in-house nested polymerase chain reaction for rapid diagnosis of tuberculous pleural effusion. Int J Med Res Rev 2016;4(5):723-730.doi: 10.17511/ijmrr.2016.i05.10. 